\title{
NEW HUNGARIAN MECHANISTIC-EMPIRICAL DESIGN PROCEDURE FOR ASPHALT PAVEMENTS
}

\author{
CSABA TÓTH ${ }^{1 *}$, PÉTER PRIMUSZ ${ }^{2}$ \\ ${ }^{1}$ Dept. of Highway and Railway Engineering, Budapest University of Technology \\ and Economics, Budapest, Hungary \\ ${ }^{2}$ Dept. of Forest Opening-up and Water Management, University of Sopron, \\ Sopron, Hungary
}

Received 21 August 2019; accepted 11 December 2019

\begin{abstract}
Certain elements of the currently used Hungarian pavement design method are based on the mechanistic-empirical pavement design principles, although they are not always readily implemented in practice. When designing a new pavement structure, it is only possible to select predetermined composition from a catalogue. The use of the Hungarian design catalogue is unquestionably comfortable, but nowadays special requirements (e.g. economy, sustainability) have been formulated as well. Those requirements increasingly call for the development of a method that can be used under Hungarian conditions, which can provide for the employment of various material properties. Instead of offering a predefined solution it needs to provide a useful tool for designers to enable realistic comparisons of engineering alternatives. This paper introduces the results of an ongoing research that aims to provide an alternative procedure for the design of newly constructed asphalt pavements. It establishes the framework for better characterization of the material properties of the natural subgrade and bound
\end{abstract}

\footnotetext{
* Corresponding author. E-mail: toth.csaba@epito.bme.hu

Csaba TÓTH (ORCID iD 0000-0001-5065-5177)

Péter PRIMUSZ (ORCID iD 0000-0002-5966-6734)

Copyright (C) 2020 The Author(s). Published by RTU Press

This is an Open Access article distributed under the terms of the Creative Commons Attribution License (http://creativecommons.org/licenses/by/4.0/), which permits unrestricted use, 
pavement layers compared to the utilization of predetermined designs. It also provides opportunity to consider local, environmental, geographical and other conditions and innovative building and technology capabilities.

Keywords: asphalt, design, layer modulus, pavement, soil improvement, structure.

\section{Introduction}

Construction of missing road network elements, strengthening or rehabilitation of the existing network items is an essential national economic concern all over the world. However, the available natural resources are limited worldwide, thus design of such developments and interventions must necessarily be carried out using state-of-the-art methods. Even if unlimited resources are available, only modern, careful and considerate planning can ensure development of efficient, low cost and/or higher service quality and more sustainable technical solutions. Engineers are constantly trying to meet the growing environmental, social and economic challenges associated with pavement design. The former empirical design principles are being constantly replaced by the mechanistic-empirical models. In addition to the studies of traffic load impact, the analysis of environmental impacts is also being increasingly incorporated in pavement design methods. Technically appropriate methods of the structural design, which has considered the environmental impacts of design inputs, must ultimately meet the increasingly stringent requirements towards economy and sustainability.

The international literature dedicated to the development and refinement of designing procedures is quite abundant, although the United States dominate in this field due to its National Cooperative Highway Research Program (NCHRP). This program has provided assess to numerous research reports for the experts. The importance of the new design method, which was developed as part of the program "The Mechanistic- Empirical Pavement Design Guide" (MEPDG), is also doubtless (Li, Xiao, Wang, Hall, \& Qiu, 2011). In Europe, the European Cooperation in Science and Technology (COST) initiated unification of different pavement design methods and launched the COST Action 333 in March 1996 with an aim to implement a new European pavement design method (COST, 1999). However, in the course of this work, it was proved that a much more thorough research is required for standardization; therefore, the AMADEUS Project (Advanced Models for Analytical Design of European Pavement Structures) was launched on January 1, 1998 (AMADEUS, 2000). The two studies mentioned above were unsuccessful 
in proposing a uniform pavement design method; however, they were valuable publications reflecting the European design trends and considering future challenges (Pereira \& Pais, 2017). The European standardization of design methods is an immense task that may seem to be almost impossible to complete due to highly sophisticated technical normative texts and protocols that have to be created. In addition, the economic viability, climatic conditions, mineral raw material reserves and the current technological capabilities of the design and construction profession of all countries have to be taken into account.

Accordingly, the papers on the development of the national design methods are published more frequently, naturally utilizing international experience and results. After extensive preparation, Germany, which had previously used only predetermined designs, created and released a new analytical pavement design method in 2009, which is extremely novel and innovative in many of its components (RDO Asphalt 09, 2009). The Austrian method has also been fundamentally developed; it has also allowed utilizing a unique pavement design method (Eberhardsteiner \& Blab, 2017). In the history of mechanistic pavement design, the French practice is considered the pioneer in the field on the world scale. This practice is not only continually optimized, it has also become an export item - other countries adapt it to their own economic and climatic conditions (Balay, Brosseaud, Bara, \& Castaneda, 2012).

\begin{tabular}{|c|c|c|c|c|c|c|}
\hline CATAL & UE FOR AS & ALT PAVEM & $S$ WITH CE & T TREATE & BASE (CTB) & AYER \\
\hline \multicolumn{7}{|c|}{ Traffic Loading Category } \\
\hline A & $\mathrm{B}$ & $\mathrm{C}$ & $\mathrm{D}$ & $\mathrm{E}$ & $\mathrm{K}$ & $\mathrm{R}$ \\
\hline \multicolumn{7}{|c|}{ Design Traffic (DT), million Equivalent Standard Axle } \\
\hline $0.03-0.1$ & $0.1-0.3$ & $0.3-1$ & $1-3$ & $3-10$ & $10-30$ & above 30 \\
\hline \multicolumn{7}{|c|}{$150 \mathrm{~mm}$ thick CTB } \\
\hline$\frac{200}{50}$ & $\frac{250}{100}$ & $\frac{280}{130}$ & $\frac{320}{170}$ & $\frac{350}{200}$ & $\frac{390}{240}$ & $\begin{array}{l}430 \\
280\end{array}$ \\
\hline 150 & 150 & 150 & 150 & 150 & 150 & 150 \\
\hline \multicolumn{7}{|c|}{$200 \mathrm{~mm}$ thick CTB } \\
\hline$\underline{240}$ & $\frac{260}{60}$ & $\frac{300}{100}$ & $\frac{340}{140}$ & $\frac{390}{190}$ & $\frac{430}{230}$ & $\begin{array}{l}\frac{470}{270} \\
\end{array}$ \\
\hline 200 & 200 & 200 & 200 & 200 & 200 & 200 \\
\hline
\end{tabular}

Figure 1. Predetermined designs with hydraulically bound base layers in the catalogue. Legend: dark grey colour represents asphalt layer, light grey colour - CTB layer and sandy yellow colour - the subgrade 
However, it is important to note that in the countries where only design catalogue-based planning is in place (Judycki et al., 2017; Vukobratović, Barišić, \& Sanja, 2017), continued effort is made to incorporate the opportunities offered by new materials and technologies into national regulations as soon as possible. In the field of pavement design and reinforcement, no significant progress was made in Hungary after the modernization of the early 1990s. Although there were substantive proposals for advancement (Karoliny \& Gáspár, 2015), so far they have not been incorporated into the regulation. As a result, the national design principles are currently outdated and the technological development has not been accounted for in the Hungarian regulation.

Apart from the comfortable use of the predetermined designs, dayto-day design tasks increasingly require a method that is simultaneously suitable for new pavement design and for the development of rehabilitation and technological proposals for the existing pavements. An old engineering requirement is that the method must be able to employ the potential of material properties along with technical comparison of alternatives of each design (e.g. extra lifetime or equivalent lifetime but cheaper structure).

This paper introduces the interim results of the research that aims to provide an alternative design procedure for the design of newly constructed asphalt pavements, which creates the framework for better utilization of the material properties of the natural subgrade and bound pavement layers compared to the utilization of predetermined designs. It also provides the opportunity to consider local, environmental, geographical and other conditions and employ innovative building and technical capabilities.

\section{The current practice of the Hungarian pavement design}

The new Hungarian pavement design method (ÚT 2-1.202:2005, 2005 ) is fundamentally based on the mechanistic-empirical pavement design principles; however, it only allows the practicing engineers to select predetermined designs from the catalogue. The currently applicable rule regulates the required asphalt thickness according to the following four base layer types depending on the design traffic:

1) predetermined designs of full-depth asphalt pavements: in the case of predetermined designs of full-depth asphalts, the base is also made of hot mix asphalt; 
2) pavements constructed with unbound granular base course, where the base can be made using the method of mechanical stabilization, using macadam or continuously graded crushedstone / aggregate as a base course;

3) pavements constructed with hydraulically bound base layers. For this base course, the designer can choose the thickness between $150 \mathrm{~mm}$ or $200 \mathrm{~mm}$;

4) pavements constructed with lean concrete base layer.

The structure and use of the design catalogue in the case of pavement with hydraulically bound base layer is shown in Figure 1. The obtained value after determining the design traffic (shown in Figure 1) must be listed in traffic load classes (marked with A-R) and the required pavement thickness can be determined from the table depending on the traffic load class. The pavements represent the solid total thickness of the asphalt layers. The designer should later divide these thicknesses to separate asphalt layers considering the constructability.

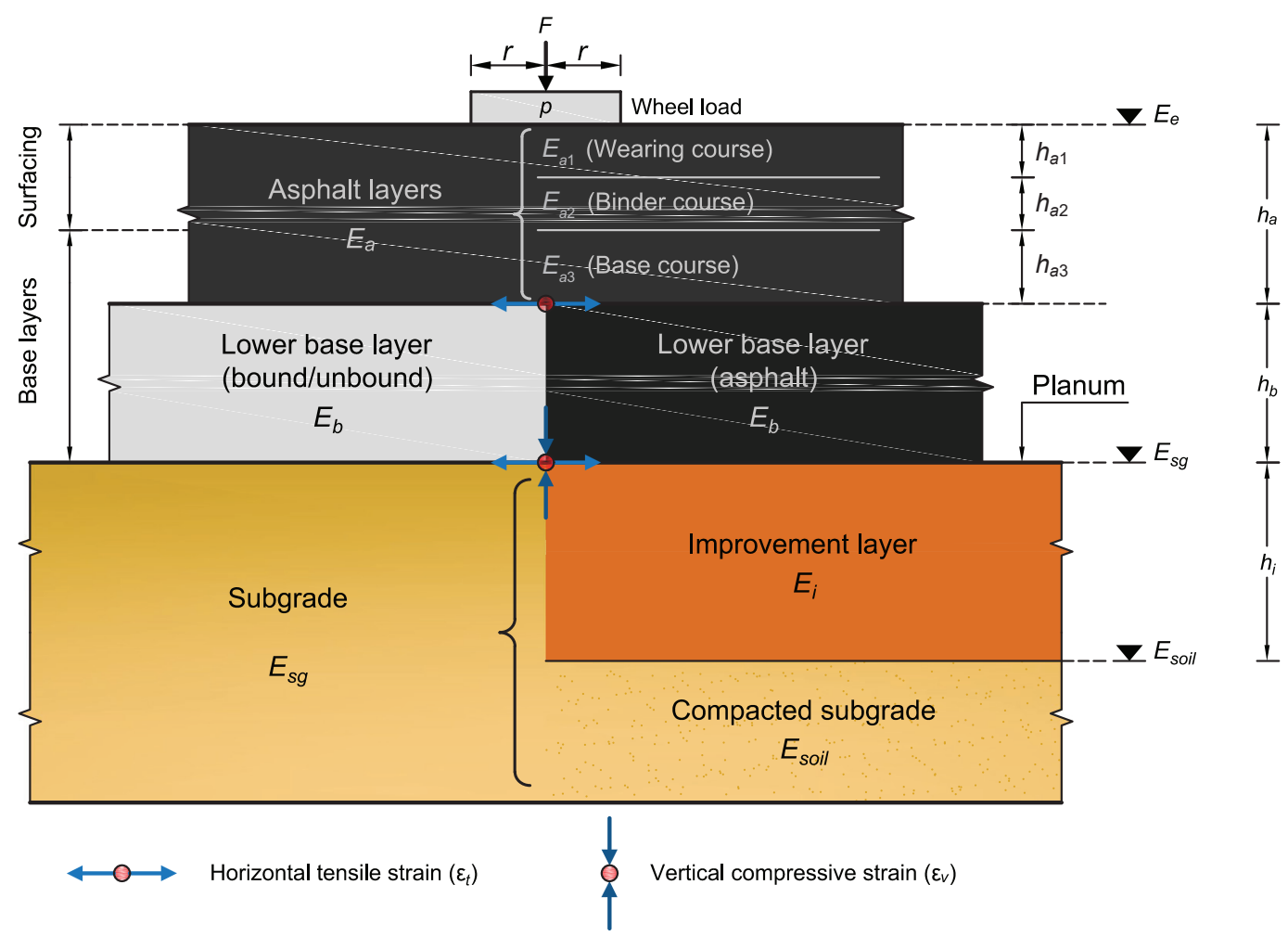

Figure 2. The design modulus and general layer composition. Symbols: $F$ - magnitude of load, $r$ - radius of load, $p$ - contact pressure, $E$ - modulus of elasticity, $\mu$-Poisson's ratio, $h$ - layer thickness, $E_{e}$ - equivalent modulus 
The design of base course constructed from lean concrete is not in use anymore due to the risk of occurrence of reflection cracks, and the full-depth asphalt pavements - although theoretical possibilities have long been available - have virtually not been constructed in Hungary. Consequently, the number of design variations has been limited to two instead of four. Taking into consideration that the country's mineral resources are not particularly favourable and the spatial distribution of quarries is uneven, the construction of unbound granular base courses has been steadily declining, therefore today the design and construction of the hydraulically bound base layers have become exclusive.

An important prerequisite of the research was that the new design method should be harmonized with the current Hungarian predetermined designs and they have to be handled together, thus ensuring the freedom of choice for the client and the designer between the two methods. In the course of development of the proposed method, the authors considered creation of an analytical toolkit of pavement design as their primary goal, but beyond that, due to the limited timeframe, it was not possible to take full account of the technological, geometrical, and constructional requirements as well as quality assurance and road safety. These issues still require further research.

\section{Principle of the proposed new pavement design method}

The method treats pavements as multi-layered, flexible mats lying on an elastic, infinite isotropic space (Burmister, 1945), which can be characterized by their thickness $(h)$, elastic modulus $(E)$ and Poisson's ratio $(\mu)$. Knowing these three parameters, and with the effect of the uniformly distributed circular load surface on the surface of the top asphalt layer, the stress, strain and displacement at any internal point of the multilayer system can be calculated (Figure 2). The method considers the tensile strain $\left(\varepsilon_{t}\right)$ at the bottom of asphalt layers and the vertical compressive strain $\left(\varepsilon_{v}\right)$ generated directly on the surface of the subgrade as critical stress and strain. Using this method, while determining the strains generating in the critical areas of the created model defined in the axes of stress with the help of the specified parameters of materials, it is considered that the structure meets the requirements if these values are lower than the values of the allowable design criteria based on material properties. 


\subsection{Steps of the implementation process}

Mechanistic-empirical design is an iterative performance-based process. The flowchart in Figure 3 represents the main steps of the design process. Creation of a three-layered model of the asphalt pavement is the starting point of the design process. Reduction of the pavement layers to the three-layered model was necessary to ensure that the developed method can be directly compared with the predetermined designs in the existing catalogue.

Calculations can be performed using the mechanistic-based parameterized multilayer elastic pavement response model. The following three layers are separated:

1) asphalt layers,

2) base course(s),

3) subgrade (foundation).

The subgrade is the in situ compacted material (local soil or improved soil layer) upon which the pavement structure is placed. Soil improvement is the alteration of any property of a soil to improve its engineering performance. The whole subgrade is modelled with infinite elastic half-space where the compacted material is replaced by elastic, homogeneous, isotropic semi-infinite continuum. In the design process,

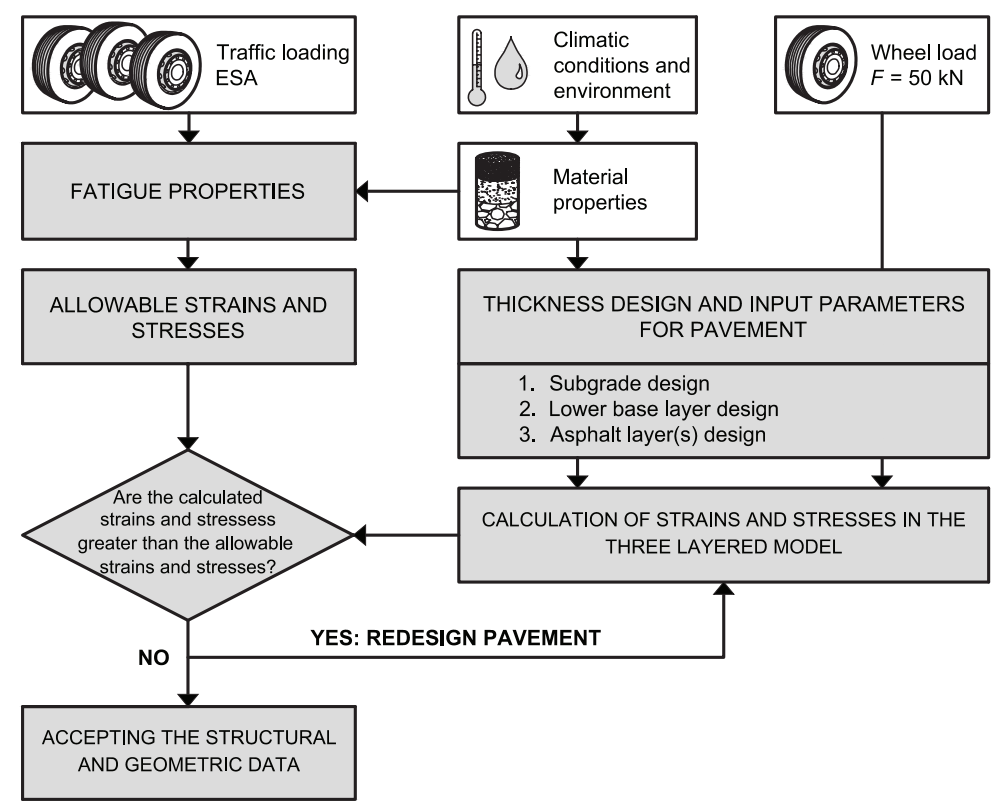

Figure 3. Workflow of the ME pavement design method
Empirical Design

Procedure for

Asphalt Pavements 
material properties $(E, \mu)$ for each layer of the three-layer system should be determined, thickness for asphalt-concrete and base course(s) should be set. Then we use the critical pavement responses and empirical pavement life equations to predict the pavement life span in terms of fatigue cracking or rutting. After the values of applied and allowable loads have been determined, we can decide on the structure.

\subsection{Material properties and design of layer thicknesses}

\subsubsection{Designing the bearing capacity of the subgrade}

The current regulation sets the static design bearing capacity modulus of the subgrade at $E_{2 m}=40 \mathrm{MPa} . E_{2 m}$ subgrade modulus is calculated by plate load test from the second loading stage. Contrary to this approach, applying the new method, the Designer can choose the design bearing capacity modulus higher than the lowest bearing

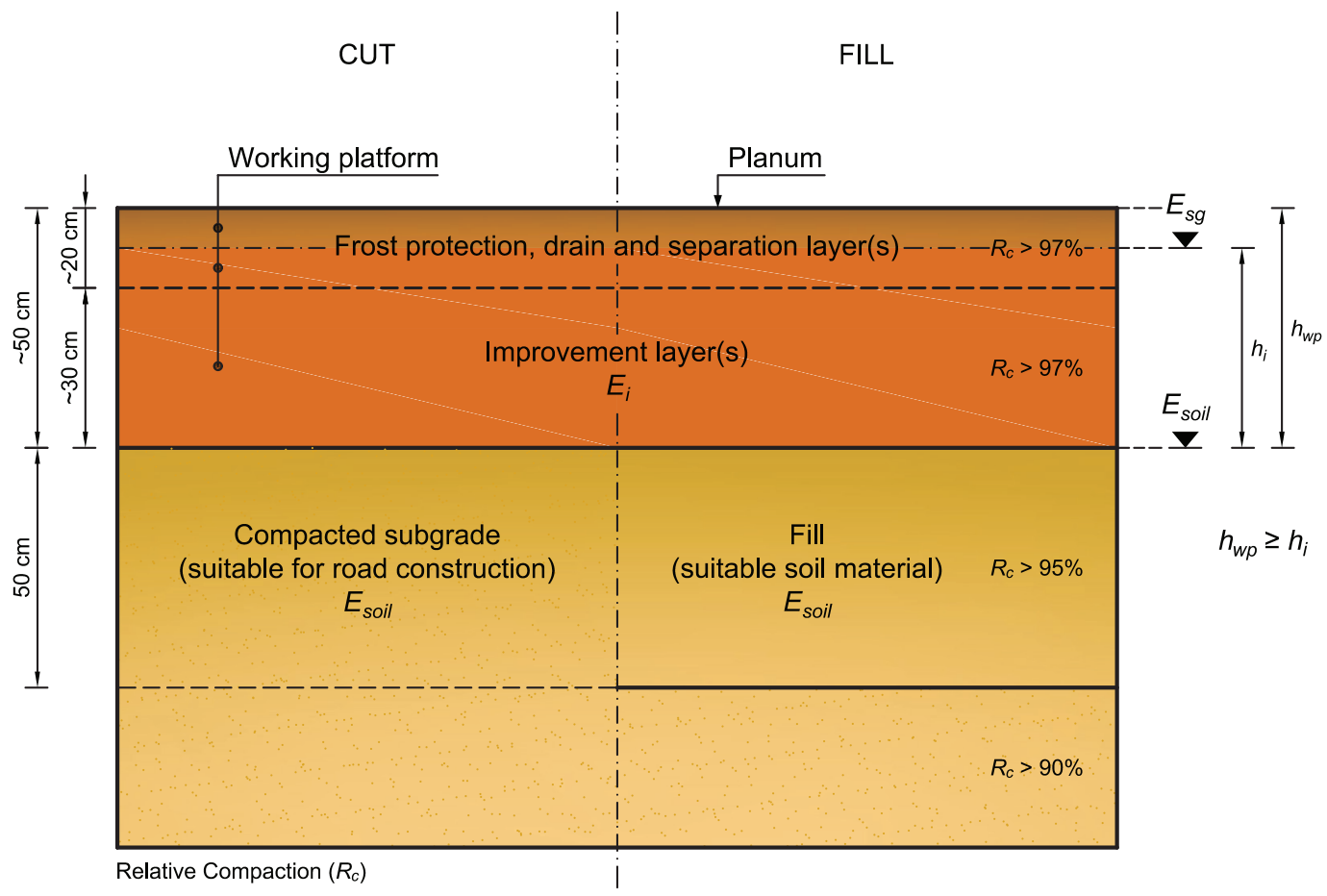

Figure 4. The characteristic structure of the upper part $(2 \mathrm{~cm} \times 50 \mathrm{~cm})$ of the subgrade during design. Symbols: $E_{s g}$ - subgrade modulus, $E_{\text {soil }}$ soil modulus, $E_{i}$ - improvement layer modulus, $h_{i}$ - thickness of improvement layer, $h_{w p}$ - thickness of working platform 
capacity of the subgrade $\left(E_{s g}=40 \mathrm{MPa}\right)$. It is recommended to consider the local soil and hydrological conditions and consciously design the best possible bearing capacity of the subgrade $\left(E_{s g}\right)$, thus avoiding the situation that the performance required from the entire pavement can only be achieved by increasing the thickness of more valuable pavement layers. Figure 4 illustrates the general model of subgrade bearing capacity design. According to the introduced model, the main steps of the subgrade bearing capacity design are as follows (Figure 5).

1. Calculation of the bearing capacity modulus of the compacted soil $\left(E_{\text {soil }}\right)$.

2. Selecting the design bearing capacity modulus of the subgrade $\left(E_{s g}\right)$.

3. If the value of bearing capacity $\left(E_{\text {soil }}\right)$ is low, i.e. $E_{\text {soil }} \ll E_{s g}$ and this requires the design (and construction) of thick pavement layers, then subgrade improvement layer has to be utilized. Otherwise, $E_{s g}=E_{\text {soil }}$ and design of the subgrade bearing capacity is completed.

4. Calculation of the bearing capacity of the improvement layer $\left(E_{i}\right)$.

5. Calculation of the necessary thickness of the improvement layer $\left(h_{i}\right)$ knowing the design bearing capacity modulus of the compacted soil $\left(E_{\text {soil }}\right)$ and subgrade $\left(E_{s g}\right)$.

6. Checking the need for frost protection, drain and separation layer.

\subsubsection{Determination of the bearing capacity of the natural subgrade}

The report on geotechnical soils drawn up during pavement design provides the basis for the subgrade design. The report on geotechnical soils presents the soil and groundwater conditions of the site based on the field tests and laboratory tests. Design bearing capacity values of the soils $\left(E_{\text {soil }}\right)$ ensuring durability, which are identified by the report on geotechnical soils, must be determined by laboratory tests, considering the change in the water content in the subgrade and its impact on the bearing capacity. The relative compaction of soil sample $\left(R_{c}\right)$, which is prepared for laboratory tests, is 95\% for granular soils and $90 \%$ for cohesive soils. The actual water content can be greater than the optimum water content with $\Delta w$ value, according to the standard (ÚT 2-1.202:2005, 2005). This way, the soil's bearing capacity can be determined at the laboratory for the construction conditions of a wellcompacted, slightly soaked subgrade. The design bearing capacity modulus $\left(E_{\text {soil }}\right)$ that is obtained as described above shall be replaced by a resilient modulus $\left(M_{r} ; E_{\text {soil }} \approx M_{r}\right)$ estimated based on the result of a triaxial test (MSZ EN 13286-7:2004, 2004), which describes the behaviour of the soils against cyclic loads or the result of a CBR test (MSZ EN 13286-47:2012, 2012). The alternative pavement design method
Empirical Design

Procedure for

Asphalt Pavements 
maximizes the dynamic bearing capacity modulus in $E_{\text {soil }} \leq 150 \mathrm{MPa}$ for the natural subgrade, however, the subgrade improvement layer(s) may also have higher values.

\subsubsection{Determination of bearing capacity modulus of the improvement layer}

The improvement layer of granular or treated material is placed at the top of the subgrade to provide a working surface and an improved foundation for the pavement, as well as to provide a wearing platform during construction. The layer can be built using different materials and different technologies. The main types of improvement layers that can be applied during design of the subgrade include:

- unbound granular improvement layer;

- granular improvement layer reinforced with geosynthetics;

- improvement layer made from soil stabilized by lime or cement binders.

Considering the local conditions, it is necessary to examine the possibility of using a higher performance improvement layer so that the technical and economic optimization of the pavements can be performed.

The unbound granular improvement layer can be constructed using mechanical stabilization or well graded crushed aggregate (WGCA), which is used for the base course during pavement construction. Other granular soils can also be utilized to construct the improvement layer, but in this case the soil should belong to excellent or high quality, well-compacted and frost resistant classes. The modulus of granular improvement layer $\left(E_{i}\right)$ must be determined at the laboratory based on the results of the cyclic or CBR tests described in Chapter 2.2.1.1.

The thickness of the unbound granular improvement layer can be effectively reduced by incorporating geosynthetic layer(s). Geotextiles, geogrids, geowebs and various composite geosynthetics can be used for this purpose (MSZ EN 13249:2014+A1:2015, 2015). Geosynthetics are available in a very wide range (different types and strengths). The manufacturers of geosynthetics develop design diagrams and software for their own products providing opportunity to determine the bearing capacity modulus of the subgrade $\left(E_{s g}\right)$ in accordance with the manufacturer's recommendations. Even so, responsibility for the satisfactory performance is placed on the designer. Knowing the thickness $\left(h_{i}\right)$ of geosynthetic-reinforced unbound granular improvement layer, the modulus of the soil to be improved $\left(E_{\text {soil }}\right)$, the bearing capacity modulus $\left(E_{i}\right)$ of the geosynthetic-reinforced unbound granular improvement layer can be calculated using Figure 6, and the result can be utilized in pavement design. 
Laboratory tests:
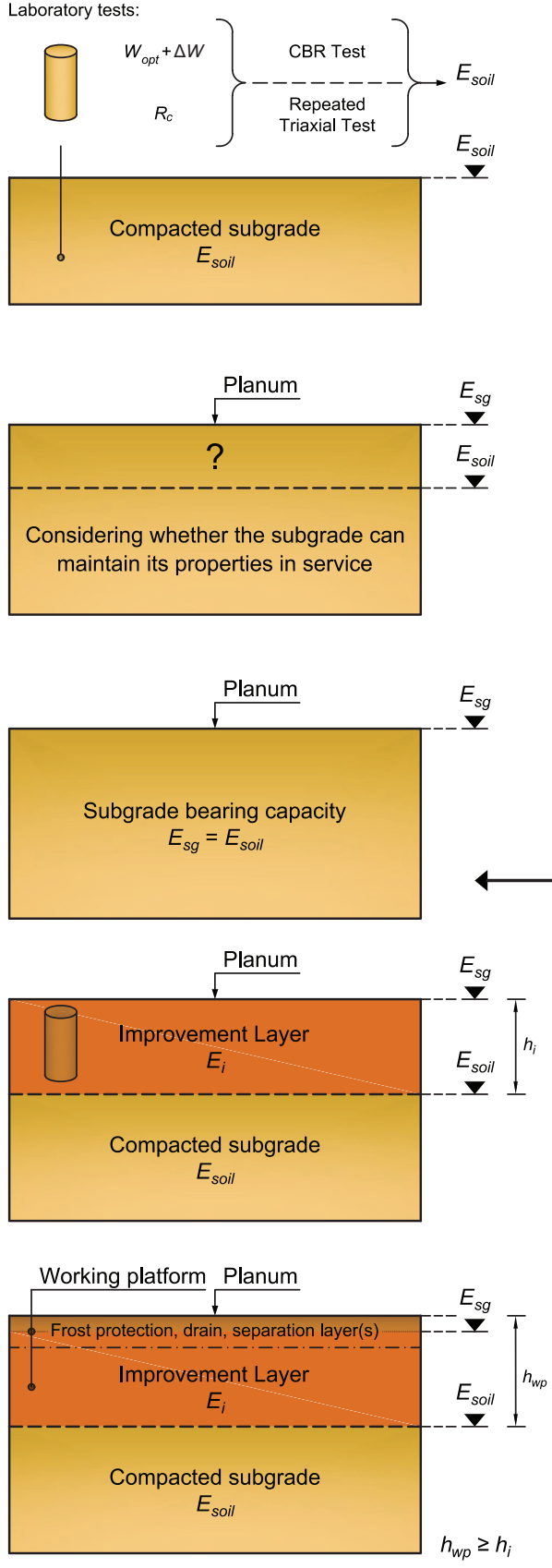

Soil Test Reports

In situ sampling and soil identification

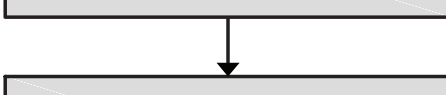

Establishing the bearing capacity of the compacted subgrade - laboratory tests

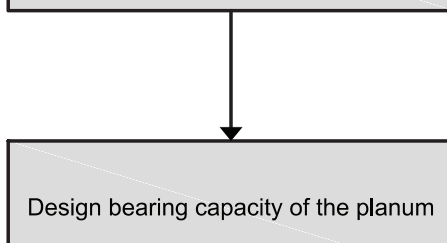

Is improvement layer required?

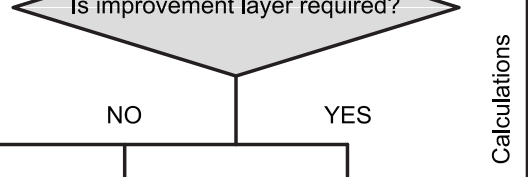

Are frost protection, drain and separation layers required?

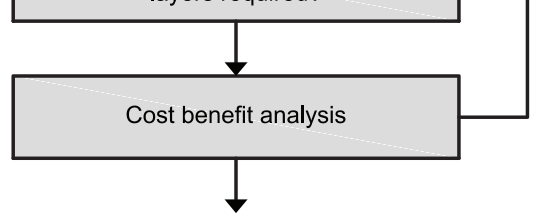

Empirical Design

Procedure for

Asphalt Pavements

\section{END}

Figure 5. Schematic representation of the workflow of the subgrade bearing capacity design 
The greatest benefit of soil stabilization by adding the binder is that it modifies the properties of in situ soils, thus they become moisture and frost-resistant materials. Changes in the soil properties should be ensured in the long term, therefore laboratory tests involving durability tests are required. They should verify that the stabilized layer has become permanently resistant to water and frost. The procedure does not provide specifications for these tests, consequently it is necessary to carry out and evaluate their results according to the technical specifications for each binder type or soil stabilization procedure.

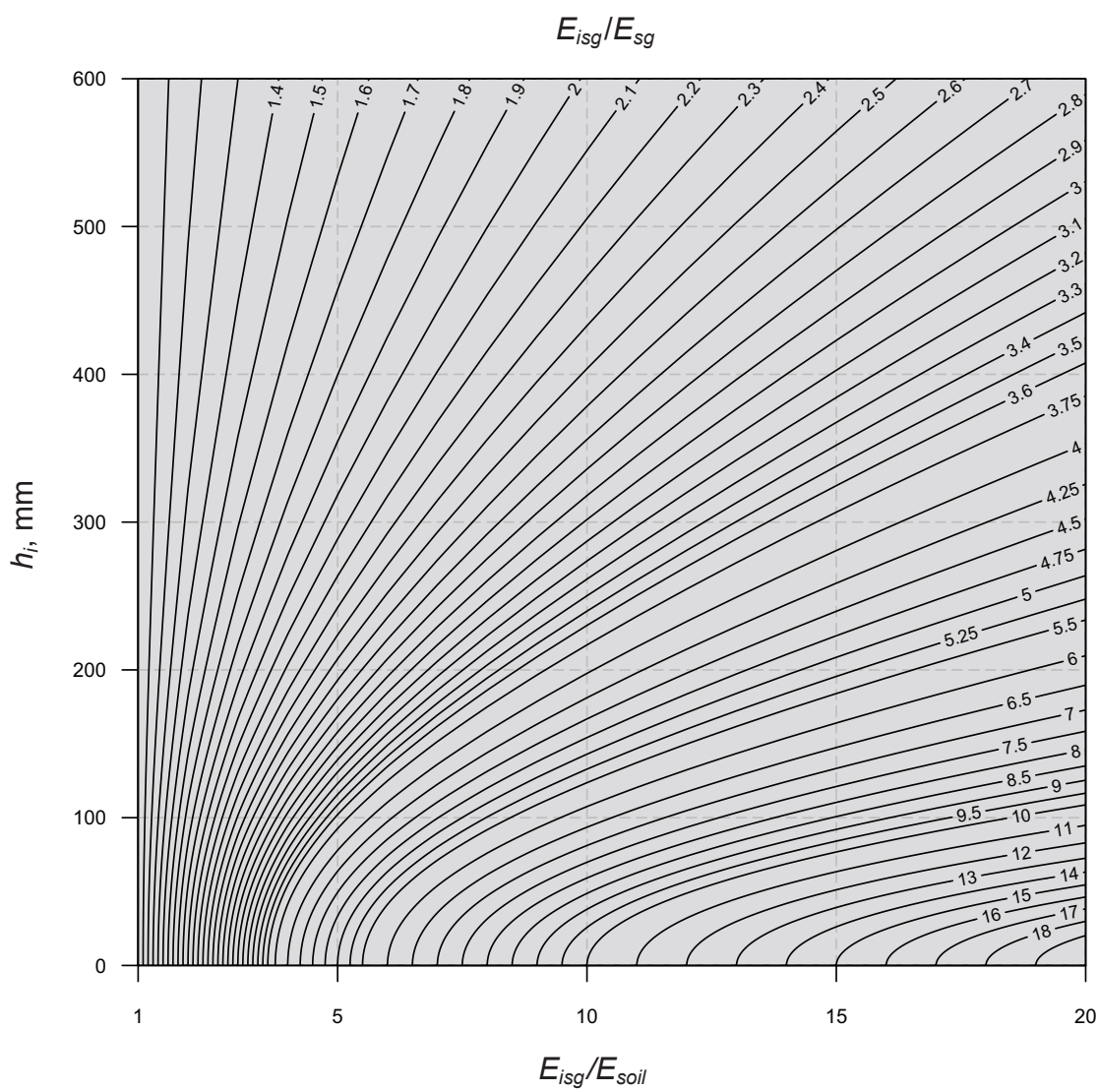

Figure 6. Determination of the subgrade improvement layer thickness ( $E_{\text {soil }}-$ modulus of the soil to be improved, $E_{i}$ - modulus of the improvement layer, $E_{s g}$ - target bearing capacity modulus at the top of the improvement layer, $h_{i}$ - thickness of the improvement layer).

Source: own development based on Adorjányi (2011) 

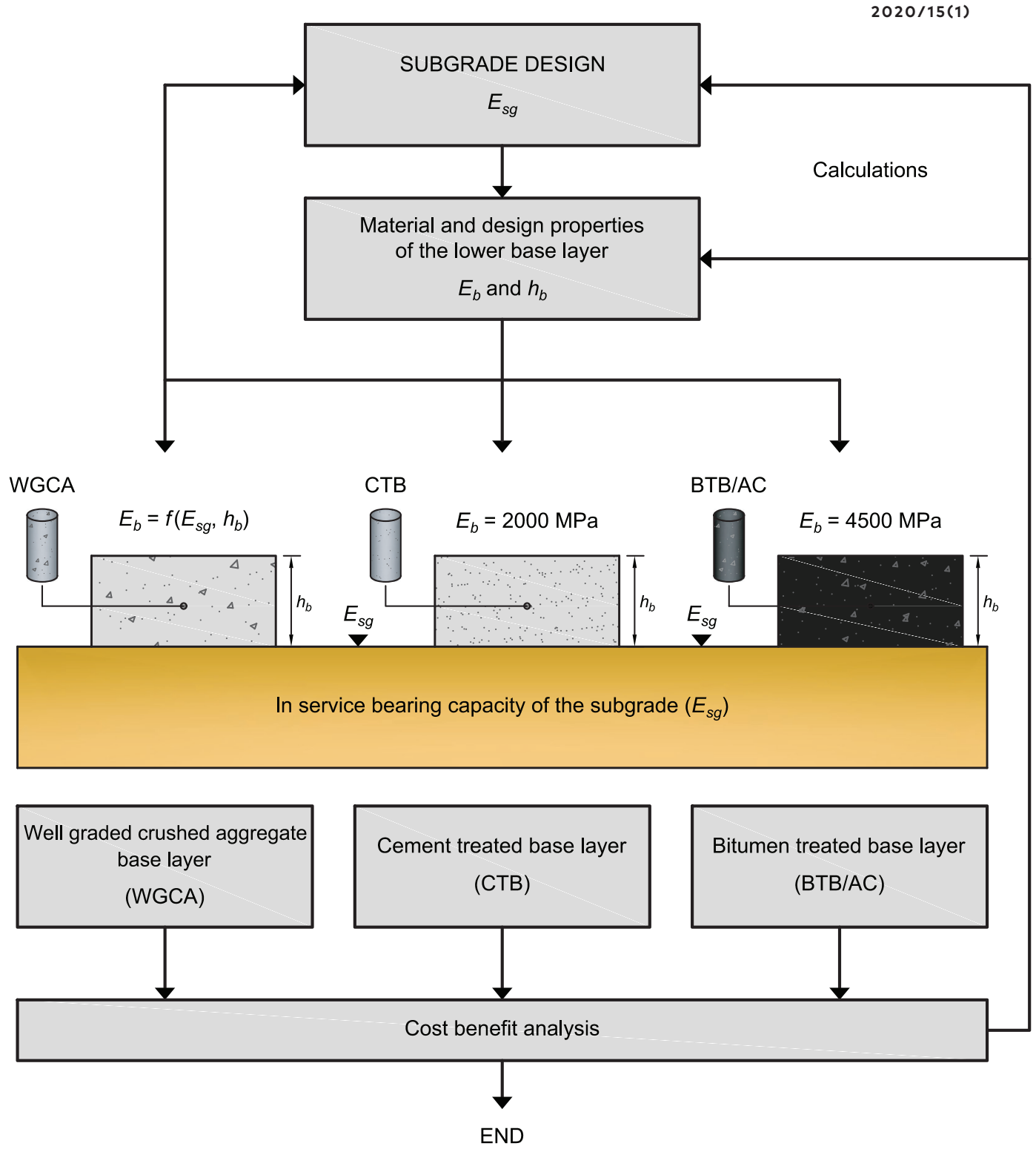

Figure 7. Workflow of the base design

The bearing capacity modulus $\left(E_{i}\right)$ of the soil stabilization improvement layer should be determined at the laboratory based on the results of the cyclic load triaxial test or CBR tests described in Chapter 2.2.1.1. 


\subsubsection{Determination of the thickness of the improvement layer}

It is recommended to determine the thickness of the improvement layer, which ensures the bearing capacity of the subgrade required by the Designer, by applying the Burmister's differential equations or Odemark's Method of Equivalent Thickness (Adorjányi, 2011). When determining the thickness of the improvement layer, it is necessary to know the bearing capacity modulus of the compacted soil under the improvement layer $\left(E_{\text {soil }}\right)$ and of the improvement layer $\left(E_{i}\right)$. Based on the known layer modulus, the improvement layer thickness $\left(h_{i}\right)$ that is necessary for achieving the planned bearing capacity $\left(E_{s g}\right)$ of the subgrade can be determined by means of the Odemark's Method of Equivalent Thickness, as shown in Figure 6.

The diagram shows the correlation amongst the modulus $\left(E_{s g}\right)$ and thickness $\left(h_{i}\right)$ of the improvement layer, the modulus of the soil to be improved $\left(E_{s o i l}\right)$ and the modulus $\left(E_{s g}\right)$ available on the top of the improvement layer (at the level of the subgrade). For the calculation, the modulus of the improvement layer has to be known, the Designer is recommended to determine it at the laboratory. The thickness of the improvement layer $\left(h_{i}\right)$ design should not be less than the maximum layer thickness. If the frost protection layer and improvement layer are made of different materials, then the thickness of the frost protection layer cannot be incorporated into the thickness of the improvement layer.

The design of the improvement layer based on the equivalent thickness is illustrated by the following example: the bearing capacity modulus of the compacted soil $\left(E_{\text {soil }}=20 \mathrm{MPa}\right)$ is improved by addition of a granular material with a modulus $E_{i}=195 \mathrm{MPa}$ to the planned bearing capacity modulus $E_{s g}=65 \mathrm{MPa}$ at the level of the subgrade. From the horizontal axis of Figure 6 , the value of $E_{i} / E_{\text {soil }}=9.75$ have to be projected to the interpolated curve $E_{i} / E_{s g}=3.0$ and the ordinate can be read by projecting the intersection on to the vertical axis to obtain the thickness of the improvement layer $\left(h_{i}=300 \mathrm{~mm}\right)$. It should be noted that in the case of $E_{i} / E_{s g} \approx 1.0$, the improvement material (and the bearing capacity modulus) cannot be efficiently applied to reach the target bearing capacity.

\subsubsection{Designing the frost protection layer}

The need for and the thickness of the frost protection layer should be determined on the basis of the current technical standards for frost protection. The thickness of the improvement layer can be included in the thickness of the frost protection layer if the built-in material meets the requirements for frost protection and is made of the same material as the frost protection layer. 


\subsubsection{Designing the separation layer}

In the case of subgrade with cohesive soil, a layer of at least $100 \mathrm{~mm}$ thick granular (sandy gravel) protection layer must be constructed under the base course of the WGCA pavement as a separation layer or geotextile shall be placed on the surface of the foundation. The thickness of the separation layer cannot be counted in the thickness of the improvement layer since its mechanical properties are different and we strive for increased safety.

\subsubsection{Designing the drain layer}

The drain layer that is used to drain water from the pavements or to interrupt capillary lift must be designed and constructed so that it can simultaneously provide the drainage, filter and support function. To ensure this, the design practice is based on the Terzaghi-type (Fannin, 2008; Terzaghi \& Peck, 1961) or on the more stringent filtering conditions, i.e. the so-called Swiss design rule for filters. The minimum thickness of the drain layer is $100 \mathrm{~mm}$, but commonly it is $150 \mathrm{~mm}$. The thickness of the drain layer cannot be added to the thickness of the improvement layer since its mechanical properties are different.

\subsubsection{Designing base course(s)}

Within the alternative pavement design method, the base course may be made from unbound aggregate and from soil binder stabilization. With regard to the binder, we distinguish cement and bitumen treated base courses. Figure 7 summarizes the base course design workflow.

\subsubsection{Unbound granular base}

The bearing capacity modulus of non-cohesive granular materials is highly dependent on their tension status, which means that they do not have their own modulus. Accordingly, it is not possible to define a specific modulus value to perform the design calculations. However, based on various regression evaluations, it is possible to determine relatively reliable design parameters. For the unbound granular materials, the well graded crushed aggregate (WGCA) can be used to construct a pavement base course(s) in the case of high traffic loads (Design Traffic $>1$ million). The modulus $\left(E_{b}\right)$ of the WGCA layer within the pavements can be determined in relation to the proposed bearing capacity of the subgrade $\left(E_{s g}\right)$ and the thickness of the base course $\left(h_{b}\right)$ with the help of diagram in Figure 8 or by the following equation:

$$
E_{b}=2.46 E_{s g}+0.64 h_{b}-54.3,
$$

where $E_{b}$ - WGCA base modulus, MPa; $E_{s g}$ - long-term design modulus of the subgrade, $\mathrm{MPa} ; h_{b}$ - thickness of the WGCA base course, $\mathrm{mm}$. 


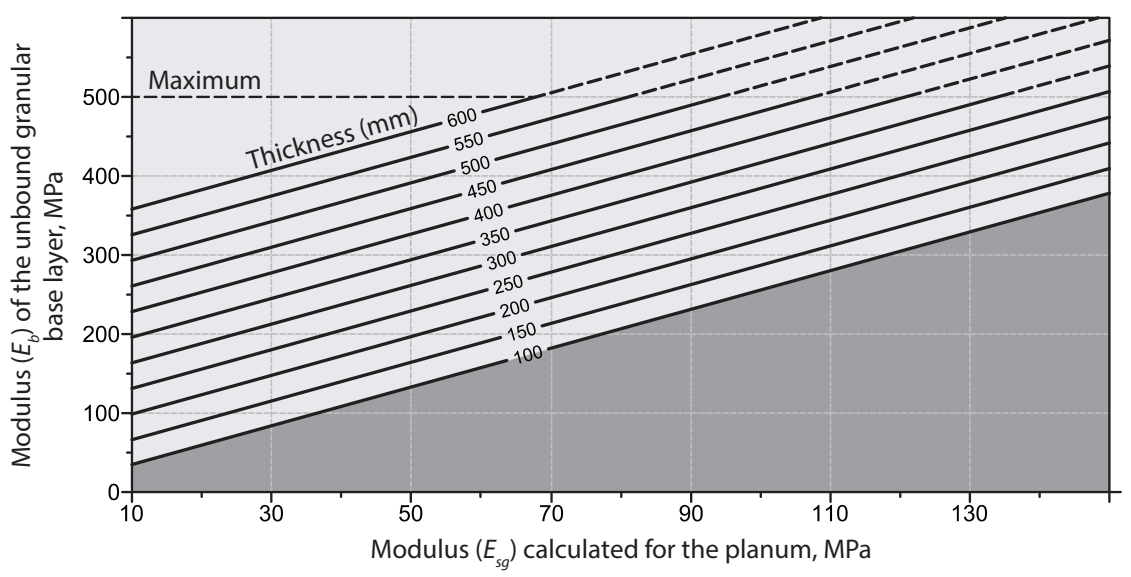

Figure 8. Determination of WGCA base modulus

Eq. (1) can be used between $10 \mathrm{MPa} \leq E_{s g} \leq 150 \mathrm{MPa}$ and $100 \mathrm{~mm} \leq h_{b} \leq 800 \mathrm{~mm}$ as thresholds with $25 \mathrm{~mm}$ increments with the constraint that the modulus of the WGCA course should also meet the $E_{b} \leq 500 \mathrm{MPa}$ condition. The minimum thickness $\left(h_{b}\right)$ of the WGCA layer is $100 \mathrm{~mm}$, while its maximum is $800 \mathrm{~mm}$ and the Poisson's ratio is $\mu=0.40$. The developed Eq. (1) is result of expert work and is based on the research of Barker et al. (1977). The general thickness $\left(h_{b}\right)$ of the WGCA base is between 200 and $300 \mathrm{~mm}$. The design thickness $\left(h_{b}\right)$ should be divided into the construction thicknesses $(v)$, considering that the largest particle size $\left(D_{\max }\right)$ cannot be greater than $1 / 3$ of the solid (compacted) layer thickness:

$$
D_{\max } \leq \frac{1}{2} v,
$$

where $v$ is the thickness of the constructed and compacted layer, typically between $100 \mathrm{~mm}$ and $200 \mathrm{~mm}$.

When designing the WGCA base courses, it is always necessary to examine whether there is a risk that the surface will rise after possible moisture impact from the natural subgrade. If so, it should be prevented by designing the foundation's bearing capacity by setting a separation layer, geotextile or a lime or cement stabilized layer.

\subsubsection{Cement treated base (CTB) course}

The cement treated base courses are a negligent area of the domestic pavement research, because there have been no relevant results in this area in the last decade, although doubts have arisen regarding the strength and fatigue characteristics of the layers. In the present study, 
we were obligated to rely on the data from previous studies, but we as soon as possible. The mechanical properties of the cement-stabilized graded aggregate (CSGA) base course that can be considered in the design process are as follows:

- Layer modulus: $E_{b}=2000 \mathrm{MPa}$;

- Poisson's ratio: $\mu=0.20$.

The minimum value of the design thickness $\left(h_{b}\right)$ is $150 \mathrm{~mm}$, while maximum thickness is $250 \mathrm{~mm}$, which can be changed by $25 \mathrm{~mm}$ increments.

\subsubsection{Bitumen treated base (BTB) course}

The bitumen treated base course is a pavement layer manufactured with the predetermined bitumen and aggregate properties. The BTB course costs less than typical hot-mixed asphalt (HMA) mixes because it can be produced with less expensive aggregates and lower percentages of bitumen binder. However, this course type is not common in the Hungarian road construction practice due to technical and economic reasons. That is why asphalt concrete is designed as the material of hot-mixed asphalt base (HMAB) course in case of full-depth asphalt pavements. The design parameters of the bitumen treated (AC) base course are:

- Layer modulus: $E_{b}=4500 \mathrm{MPa}\left(20^{\circ} \mathrm{C}\right)$;

- Poisson's ratio: $\mu=0.35$.

When designing the minimum or maximum thickness $\left(h_{b}\right)$, the requirements for construction of thicknesses should be considered. In the case of full-depth asphalt pavements, the standard tensile strain $\left(\varepsilon_{t}\right)$ should not be determined at the bottom of the asphalt layers, but at the bottom of the asphalt lower base layer of concrete (shown in Figure 2).

\subsubsection{Designing the asphalt pavement structure}

The modulus of asphalt layers depends heavily on the constantly changing temperature of the pavement. Due to temperature dependence, determination of the residual service life value of a multi-layered pavement model would require a long and complicated series of calculations because of the different values of asphalt modulus. Instead, the present method - utilizing the Miner's hypothesis - uses equivalent temperatures and asphalt modulus values for each layer, which, if they remain unchanged throughout the whole year, would result in the same fatigue damage in the pavements as the combined effect of the strains of the different asphalt moduli of different temperatures (Fi \& Pethö, 2008; Pethő, 2008).

Design parameters of the asphalt wearing-, binder- and base courses are summarized in Table 1 . In the context of design, the standard and 
Table 1. Typical equivalent asphalt modulus for design

\begin{tabular}{lccc}
\hline Asphalt course & $\begin{array}{c}\text { Equivalent stiffness } \\
\text { modulus of the asphalt } \\
\text { concrete at } 20^{\circ} \mathbf{C}, \mathbf{M P a}\end{array}$ & $\begin{array}{c}\text { The volume of } \\
\text { bitumen in asphalt } \\
\text { mixture, \% }\end{array}$ & $\begin{array}{c}\text { Poisson's } \\
\text { ratio }\end{array}$ \\
\hline Wearing course & 4000 & 12.8 & 0.35 \\
\hline Binder course & 5800 & 11.4 & 0.35 \\
\hline Base course & 4500 & 11.0 & 0.35 \\
\hline
\end{tabular}

polymer modified bitumen (PmB) asphalt mixes have the same modulus. Asphalt layers with different moduli have to be merged into one layer to establish a three-layer pavement model (Pethő \& Tóth, 2014; Pronk, 1994).

The aggregated modulus of two asphalt layers is equal to the lower layer's modulus $E_{a}=E_{a 2}$ and its thickness $\left(h_{a}\right)$ can be calculated using weight function according to Eq. (3):

$$
H_{a}=\left[\frac{A^{4}+4 A^{3} N+6 A^{2} N+4 A N+N^{2}}{(A+1)^{3}(A+N)}\right]^{\frac{1}{3}}\left(h_{a 1}+h_{a 2}\right),
$$

where

$$
\begin{gathered}
A=\frac{h_{a 2}}{h_{a 1}}, \\
N=\frac{E_{a 1}}{E_{a 2}},
\end{gathered}
$$

where $E_{a}$ - equivalent modulus of the asphalt layers, MPa; $E_{a i}$ - modulus of the $i$-th asphalt layer $(i=1, \ldots, n), \mathrm{MPa} ; h_{a}$ - equivalent thickness of the asphalt layers, mm; $h_{a i}$-thickness of the $i$-th asphalt layer $(i=1, \ldots$, $n)$, $\mathrm{mm}$.

The asphalt layers are counted from top to bottom, with $E_{a 1} ; E_{a 2}$ and $E_{a 3}$ stiffness and with $h_{a 1} ; h_{a 2}$ and $h_{a 3}$ thickness layers lying on the base course or on the subgrade. By combining the top two asphalt layers, the multilayer system can be transformed in the following steps.

1. From the top, the first $\left(E_{a 1}, h_{a 1}\right)$ and second $\left(E_{a 2}, h_{a 2}\right)$ pavement layers should merge into an equivalent layer, resulting in a layer characterized by $E_{a}=E_{a 2}$ and $h_{a}$ parameters.

2. The equivalent layer $\left(E_{a}, h_{a}\right)$ should merge with the layer found in the next row $\left(E_{a 3}, h_{a 3}\right)$ to produce a new layer characterized by $E_{a}=$ $E_{a 3}$ and $h_{a}$ parameter. 
3. The first two steps should be continued until all asphalt layers Empirical Design above the base course or the subgrade are merged into one layer, which is equivalent to the original layer order $\left(E_{a}, h_{a}\right)$.

\subsection{Calculation of strains in the pavement}

The following characteristics of each layer of the three-layer mechanical model are used to design the pavements:

- $\quad$ elastic modulus $E, \mathrm{MPa}$;

- Poisson's ratio $\mu$; and

- layer thicknesses $h, \mathrm{~mm}$.

The load ( $0.7 \mathrm{MPa})$ is calculated from the loading force $(50 \mathrm{kN})$ of one wheel of a $100 \mathrm{kN}$ equivalent single axle distributed on a $150 \mathrm{~mm}$ radius circular plate.

Even the replacement of a realistic pavement with a three-layer system is a significant simplification; however, the determination of strains is still a very large computing task and its practical implementation requires the usage of difficult graphs and tables or computer software. Considering this, an online available software (ELZA) was developed to support this method and to perform the required calculations, but these can be done by a number of suitable, commercially available design software tools (e.g. Bitumen Stress Analysis in Roads (BISAR), WESLEA for Windows). With the appropriate computing support, the following strains have to be defined in the load axis in the three-layer pavement model:

A. Horizontal tensile strain $\left(\varepsilon_{t}\right)$ at the bottom of the asphalt layer in microstrain

$$
\varepsilon_{t}=\varepsilon_{\text {standard }}^{\text {asphalt }}(\mu \text { strain }) \text {. }
$$

B. Vertical compressive strain $\left(\varepsilon_{v}\right)$ at the top of the subgrade in microstrain

$$
\varepsilon_{v}=\varepsilon_{\text {standard }}^{\text {subgra }}(\mu \text { strain). }
$$

\subsubsection{Determination of the design criteria}

\subsubsection{Determination of the pavement design traffic}

Determination of the design traffic (DT) does not deviate from the current Hungarian practice, with only one stipulation: the use of this method is only allowed over 1 million equivalent single axle loads. 


\subsubsection{Determination of the fatigue properties of the material}

One criterion for the analytical design method is that the tensile strains at the bottom of the connected asphalt layers should not be larger than the fatigue limit design criteria of the respective load level based on the Wohler curve of the respective asphalt material. The allowed equivalent single axle load (ESAL) for a given load level can be determined by the following Eq. (8) (Harrison \& Jameson, 2012):

$$
N_{\text {allowed }}=\frac{F}{S F}\left[\frac{10^{4}\left(0.856 V_{b}+1.08\right)}{E_{a}^{0.36} \varepsilon_{t}}\right]^{5},
$$

where $N_{\text {allowed }}$ - allowed equivalent single axle load (ESAL); $V_{b}$ - volume of bitumen according to Table 1, \%; $E_{a}$ - asphalt layer modulus according to Table 1, MPa; $\varepsilon_{t}$ - calculated tensile strain ( $\mu$ strain); $S F$ - shift factor, depends on the type of the base course; $F$ - reliability factor, depends on the type of the lowest asphalt layer.

The value of the shift factor $(S F)$ :

- unbound granular base course (WGCA): $S F=3.00$;

- cement treated base course (CTB): $\quad S F=2.50$;

- base course with bitumen binder (BTB): $S F=5.00$.

According to the requirements of the research, asphalt mixtures with traditional and modified binder were also distinguished. Considering that reliable Hungarian research results are not available for asphalt mechanical parameters with different binders, the hypothetical effect of the modification was considered indirectly by introducing a so-called reliability factor $(F)$ :

- traditional road construction bitumen (normal): $\quad F=1.00$;

- polymer modified bitumen (PmB): $\quad F=1.50$.

The use of fatigue curve ensures determination of allowed strains or stresses. By transforming the relation (Eq. 8) and by introducing $N_{\text {allowed }}=D T$, we get the allowed tensile strain at the bottom asphalt for design traffic (Eq. 9):

$$
\varepsilon_{\text {allowed }}^{\text {aspalt }}=\left(\frac{F}{S F}\right)^{0.2}\left[\frac{10^{4}\left(0.856 V_{b}+1.08\right)}{E_{a}^{0.36} T F^{0.2}}\right],
$$

where variables should be interpreted as before. No relevant Hungarian research results were available for the vertical compressive strain criterion at the top subgrade, therefore, the revised (stricter) correlation of the Belgian CRR Research Institute (Verstraeten, Veverka, \& Francken, 1982) is applicable according to the equation below:

$$
\varepsilon_{\text {allowed }}^{\text {subgrad }}=\frac{6000}{D T^{0.23}},
$$


where $\varepsilon_{\text {allowed }}^{\text {subgrade }}$ - allowed vertical compressive strain ( $\mu$ strain); DT design traffic in equivalent single axle load (ESAL).

\subsubsection{Implementation of the design method}

According to the principle of the analytical design, the standard strains from the load during the design lifetime cannot exceed the allowed strains determined based on the expected equivalent single axle load. The checking is completed as follows:

$$
\varepsilon_{t}=\varepsilon_{\text {standard }}^{\text {asphalt }} \leq \varepsilon_{\text {allowed }}^{\text {asphalt }}
$$

and

$$
\varepsilon_{v}=\varepsilon_{\text {standard }}^{\text {subgrade }} \leq \varepsilon_{\text {allowed }}^{\text {subgrade }}
$$

If the calculated - standard - strain is greater than the allowed design criteria, then the structure does not meet the requirements, and the recalculation of the material properties and the layer thicknesses are necessary. If the calculated - standard - strain is less than the allowed design criteria, then the structure does meet the requirements, and after the checking of oversizing, the layer thicknesses should be finalized according to the applied technology.

Care should be taken when designing thin asphalt layers, especially in the case of rigid base courses, since the strains in the pavement can meet the requirement (mentioned above) for two thickness values. In order to avoid the risk of ambiguous solutions and minimize the risk of reflection cracking, the minimum asphalt thickness of asphalt pavements constructed on the CTB base course cannot be less than $150 \mathrm{~mm}$.

\subsubsection{Checking the designed pavement structure for frost protection}

The designed pavement must be checked to prevent the damage from freeze-thaw effects. Furthermore, the plan and design of the required thickness of the frost protection layer must be performed. If it is not appropriate, the thickness or material of the layers needs to be changed and re-design is required as well.

\subsubsection{Proposed equivalence of the pavements}

Considering that the difference between the planned and realized life span of the pavements may be surprisingly wide, it may be desirable to consider wider range of loads, when comparing each pavement with respect to technical equivalence. Thus, when examining the technical equivalence of designed pavements, their direct comparison, during the pavement design method, such as the discrete values of the allowed repetitions to failure, with regard to 
the large standard deviation, may be misleading. Consequently, it is appropriate to fix equivalence by means of a threshold value in relation to the bearing capacity according to Table 2. According to the proposed definition of the method, two pavements are technically equivalent, if the calculated standard strain at the bottom asphalt layer falls within the same strain range.

\subsubsection{The results of the method in context of the current practice}

The most important issue for the professional public is how the results of the alternative method relate to the predetermined designs. During this research, a number of sensitivity tests were performed based primarily on the results of the WESLEA programs and on the ELZA, which were developed for the procedure. Figure 9 illustrates the processing of a series of results pertaining to sample calculation.

The series of calculations shows the result obtained with a $15 \mathrm{~cm}$ thick hydraulically-bound base layer, which is also included in the predetermined designs. The stepped curve in Figure 9 shows the specified value of the total asphalt thickness that is applicable to different traffic load classes in the range of $170 \mathrm{~mm}$ to $280 \mathrm{~mm}$. The other 3 curves in Figure 9 represent the values of asphalt thickness proposed by analytical design for different subgrade stiffness.

The curve corresponding to $50 \mathrm{MPa}$ stiffness gives asphalt layer thicknesses that are about the same as the current design practice. Considering traffic class " $D$ ", the proposed curve determines $20 \mathrm{~mm}$ thinner layer than the current regulation at the lower traffic limit of the class and $20 \mathrm{~mm}$ thicker layer at the upper traffic limit of the class. For the whole traffic range of traffic class " $\mathrm{D}$ ", the proposed method requires layer thickness similar to the current design regulations.

In higher traffic load classes, however, the designed asphalt thickness requirement increases, compared to the current regulation. Although if we consider the opportunities offered by the method and increase the load capacity of the subgrade (e.g. considering other two curves ( $80 \mathrm{MPa}$ or $140 \mathrm{MPa}$ ), then significant asphalt thickness savings can be achieved.

Table 2. Brackets for the technical equivalence

\begin{tabular}{cccccccc}
\hline \multicolumn{7}{c}{ Equivalent ranges of the standard asphalt strain values ( $\boldsymbol{\mu}$ strain) } \\
\hline$>220$ & $200-220$ & $175-200$ & $140-175$ & $110-140$ & $100-110$ & $<100$ \\
\hline \multicolumn{7}{c}{ Mark of the technically equivalent range } \\
\hline I. & II. & III. & IV. & V. & VI. & VII. \\
\hline
\end{tabular}




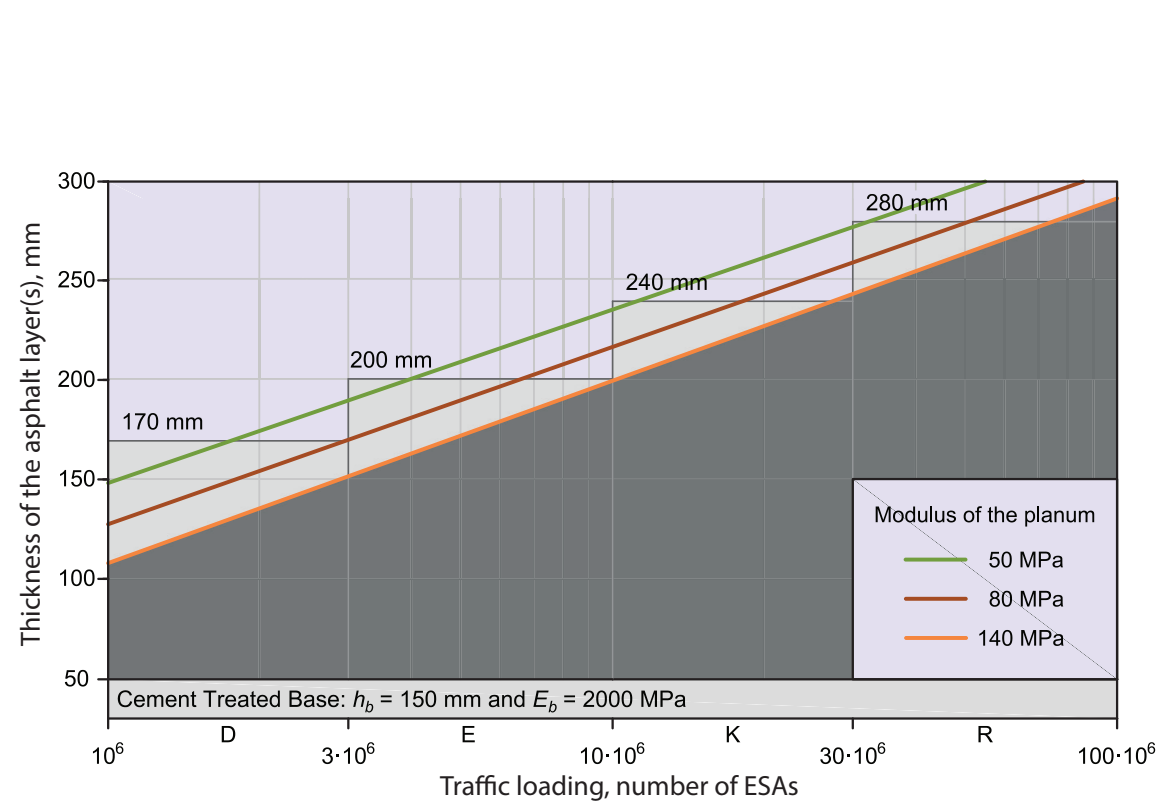

Figure 9. Comparison of the alternative method and the asphalt thickness requirements of a predetermined design

During the test calculations, material parameters given earlier were utilized, typically based on the theoretical models or on the literature data, since reliable Hungarian measurement results were unfortunately not available. Eliminating these shortcomings as soon as possible is essential, because the results we have obtained can be significantly influenced by later input parameters based on real Hungarian research results. For example, the determination of the vertical compressive strain criterion for the subgrade, the arrangement of the time-varying stiffness and fatigue characteristics of the cement stabilized base course, or the effect of the modifying products on the asphalt mechanical properties of the asphalt mixtures are all essential issues. They should be addressed as soon as possible not only to accomplish the proposed alternative designing method, but to validate of any Hungarian proposals.

\section{Summary}

This article has reviewed some results as part of a comprehensive research. An important boundary condition of the research was that the Hungarian measurements could not be done due to short time span, hence, Hungarian adaptation of the existing international results and known mechanical method(s) could only take place. 
Furthermore, it was a basic requirement that the proposed method should only be considered as an alternative to the Hungarian technical regulation for a transitional period. Adopting this approach, it is possible to introduce an alternative design method in the shortest possible time as a new element in the current technical regulation, while retaining the possibility of designing a new pavement under the current regulation. In addition to the existing professional stability, this duality is capable of ensuring gradualism in the current Hungarian design and construction practice, which guarantees that the public procurement procedures in the future will not result in unexpected negative consequences, such as the misalignment of the applicable regulatory elements, lack of design skills, etc.

The proposed analytical procedure offers significant simplifications. However, it is expected to be the first step in the future in Hungary to provide a modern, mechanically based pavement design method that significantly increases the designer's room to manoeuvre compared to the predetermined designs. Moreover, it can help handle possible technological changes in the future, also with regard to energy saving and environmental protection.

\section{REFERENCES}

Adorjányi, K. (2011). Effect of Capping Layers on the Improvement of Subgrade Bearing Capacity. In Proceedings of 11th International Scientific Conference (MOBILITA '11). Bratislava, 26-27 May 2011.

AMADEUS. (2000). AMADEUS: Advanced Models for Analytical Design of European Pavement Structure. R0-97-SC.2137. The European Commission under the Transport RTD Programme of the 4th Framework Programme. https:// trimis.ec.europa.eu/project/advanced-models-analytical-design-europeanpavement-structures

Balay, J. M, Brosseaud, Y., Bara, B., \& Castaneda, E. (2012). Adaptation of the French Pavement Design to Countries in South America. Congrès 8eme Jornadas International Des Asfalto.

Barker, W. R., Brabston, W. N., \& Chou, Y. T. (1977). General System for the Structural Design of Flexible Pavements. In Proceedings of 4th International Conference on Structural Design of Asphalt Pavements (vol. 1, pp. 209-248). Ann Arbor, Michigan, 22-26 August 1977.

Burmister, D. M. (1945). The General Theory of Stresses and Displacements in Layered Systems. I. Journal of Applied Physics, 16(2), 89-94. https://doi.org/10.1063/1.1707558

COST. (1999). COST 333: Development of New Bituminous Pavement Design Method; Final Report of the Action. EUR 18906. Luxembourg: Office for Official Publ. of the Europ. Communities. 
Eberhardsteiner, L., \& Blab, R. (2017). Design of Bituminous Pavements - a Performance-Related Approach. Road Materials and Pavement Design, 20(2), 244-258. https://doi.org/10.1080/14680629.2017.1380689

Fannin, J. (2008). Karl Terzaghi: From Theory to Practice in Geotechnical Filter Design. Journal of Geotechnical and Geoenvironmental Engineering, 134(3), 267-76. https://doi.org/10.1061/(ASCE)1090-0241(2008)134:3(267)

Fi, I., \& Pethő, L. (2008). Calculation of the Equivalent Temperature of Pavement Structures. Periodica Polytechnica Civil Engineering, 52(2), 91. https://doi.org/10.3311/pp.ci.2008-2.05

Harrison, C., \& Jameson, G. (2012). Guide to Pavement Technology: Part 2: Pavement Structural Design. 3rd ed. Sydney, NSW 2000 Australia: Austroads Ltd.

Judycki, J., Piotr, J., Marek, P., Ryś, D., Jaczewski, M., Alenowicz, J., Dołżycki, B \& Stienss, M. (2017). New Polish Catalogue of Typical Flexible and Semi-Rigid Pavements. In MATEC Web of Conferences, 122, 04002. https://doi.org/10.1051/matecconf/201712204002

Karoliny, M., \& Gáspár, L. (2015). Investigation and Design of Durable Pavement Structure Rehabililation. International Journal on Pavement Engineering \& Asphalt Technology, 16(1), 30-54. https://doi.org/10.1515/ijpeat-2015-0002

Li, Q., Xiao, D. X., Wang, K. C. P., Hall, K. D., \& Qiu, Y. (2011). Mechanistic-Empirical Pavement Design Guide (MEPDG): A Bird's-Eye View. Journal of Modern Transportation, 19(2), 114-33. https://doi.org/10.1007/bf03325749

MSZ EN 13286-7:2004. (2004). Unbound and hydraulically bound mixtures. Part 7: Cyclic load triaxial test for unbound mixtures.

MSZ EN 13286-47:2012. (2012). Unbound and hydraulically bound mixtures. Part 47: Test method for the determination of California bearing ratio, immediate bearing index and linear swelling.

MSZ EN 13249:2014+A1:2015. (2015). Geotextiles and geotextile-related products. Characteristics required for use in the construction of roads and other trafficked areas (excluding railways and asphalt inclusion)

Pereira, P., \& Pais, J. (2017). Main Flexible Pavement and Mix Design Methods in Europe and Challenges for the Development of an European Method. Journal of Traffic and Transportation Engineering (English Edition), 4(4), 316-346. https://doi.org/10.1016/j.jtte.2017.06.001

Pethő, L. (2008). Influence of Temperature Distribution on the Design of Pavement Structures. Periodica Polytechnica Civil Engineering, 52(1), 45-53. https://doi.org/10.3311/pp.ci.2008-1.07

Pethő, L., \& Tóth, Cs. (2014). The Development of Pavement Rehabilitation Design Guidelines for Increasing the Allowable Axle Load from $100 \mathrm{kN}$ to 115 kN. In Y. Kim (Ed.), Asphalt Pavements (pp. 1577-1586). CRC Press. https://doi.org/10.1201/b17219-191

Pronk, A. C. (1994). Equivalent Layer Theories: State of the Art Report. W-DWW-94-904. DWW Werkdocument. Delft, Netherlands 2628 CS: Dienst Wegen Waterbouwkunde (DWW). 
RDO Asphalt 09. (2009). Richtlinien für die rechnerische Dimensionierung des Oberbaus von Verkehrsflächen mit Asphaltdeckschicht: RDO Asphalt 09. Report FGSV-498. FGSV. Köln: Forschungsgesellschaft für Straßen- und Verkehrswesen (FGSV).

Terzaghi, K., \& Peck, R. P. (1961). Die Bodenmechanik in der Baupraxis [Soil Mechanics in Building Construction]. Berlin, Heidelberg: Springer. https://doi.org/10.1007/978-3-642-92829-1

ÚT 2-1.202:2005. (2005). Aszfaltburkolatú útpályaszerkezetek méretezése és megerösítése [Designing and strengthening of asphalt pavements]. Útügyi Műszaki Előírás. (in Hungarian).

Verstraeten, J., Veverka, V., \& Francken, L. (1982). Rational and Practical Designs of Asphalt Pavements to Avoid Cracking and Rutting. In Proceedings Fifth International Conference on Structural Design of Asphalt Pavements, (vol. 1, pp. 45-58). Delft University of Technology.

Vukobratović, N., Barišić, I., \& Sanja, D. (2017). Analyses of the Influence of Material Characteristics on Pavement Design. Elektronički Časopis Građevinskog Fakulteta Osijek, 8-19. https://doi.org/10/gfj4g9 